\title{
Use of Micrometers and Calipers to Measure Various Components of Delayed-Type Hypersensitivity Ear Swelling Reactions in Mice*
}

\author{
Henk Van Loveren ${ }^{1}$, Kazuyuki Kato ${ }^{2}$, Robert E. Ratzlaff ${ }^{3}$, \\ Robin Meade ${ }^{3}$, Wlodzimierz Ptak ${ }^{4}$ and Philip W. Askenase ${ }^{3},{ }^{* *}$ \\ ' Department of Pathology, Pasteurstraat 2, $3511 \mathrm{HX}$ Utrecht, The Netherlands, ${ }^{2}$ Institute of Immunological \\ Science, Hokkaido University, Kita-ku, Sapporo 060, Japan, ${ }^{3}$ Department of Internal Medicine, Yale \\ University, School of Medicine, 333 Cedar Street, New Haven, CT 06510, U.S.A., and ${ }^{4}$ Department of \\ Immunology, Copernicus Medical School, Cracow, Poland
}

(Received 4 October 1983, accepted 17 October 1983)

The choice of the type of instrument to measure delayed-type hypersensitivity (DTH) in mice, as assayed by ear swelling reactions, influences the experimental results. When a caliper that applies little pressure to the ears is employed, DTH reactions in ears of mice sensitized to picryl chloride show an early onset at $2 \mathrm{~h}$ after challenge, comparable swelling at $4 \mathrm{~h}$ and a slow rise to a $24 \mathrm{~h}$ classical peak response thereafter. In contrast, 3 different micrometers that apply more pressure to the ears reveal a biphasic pattern of ear swelling reactions in mice immunized and challenged with picryl chloride. The early component of DTH measured by these micrometers peaks $2 \mathrm{~h}$ after challenge. Thereafter the measured ear thickness declines, and the onset of the classical delayed reaction is detected at $12 \mathrm{~h}$ after ear challenge. Yet another instrument, that in contrast to the caliper and micrometers mentioned above, applies all the pressure to only a very restricted area of the ear, fails to detect an early swelling reaction; the delayed reaction is first detected at $12 \mathrm{~h}$ after ear challenge and rises thereafter to a $24 \mathrm{~h}$ peak.

The differences in outcome of the assays using the different instruments indicate that the early component or DTH reactions differs from the late component of DTH reactions in that the early swelling is easier to compress when pressure is applied by the instrument used for measurement. This is probably caused by the fact that the late reactions are due to a cellular infiltrate, whereas the early reactions are edematous in character, and are due to accumulation of plasma components.

Key words: delayed-type hypersensitivity - contact hypersensitivity - mice

\footnotetext{
* Supported in part by grants from the Netherlands Organization for the Advancement of Pure Research (ZWO); the Netherlands Cancer Society (KWF); the Maria Sklodowska-Curie Fund (Polish American Agreement $05.042 \mathrm{~N}$ ); the Polish Academy of Sciences (10.5); and by Grants from the United States Public Health Service, National Institutes of Health nos. AI-12211, AI-17555, AI-11077, CA-29606, AI-10497 and training Grant AI-07174.

** To whom correspondence should be sent.

Abbreviations: DTH, delayed-type hypersensitivity; PCL, picryl chloride.
} 


\section{Introduction}

We have noted recently that several types of delayed-type hypersensitivity (DTH) reactions in mice have a biphasic pattern of macroscopic tissue swelling (Van Loveren et al., 1983a). This is exemplified by picryl chloride (PCL) painting to challenge the ears of CBA mice that were contact sensitized with PCL 4 days earlier. There is an early ear swelling reaction that peaks $2 \mathrm{~h}$ after challenge, followed by a decline in ear thickness $4 \mathrm{~h}$ after ear challenge. A second ear swelling reaction then peaks $24 \mathrm{~h}$ after challenge, representing the classical delayed-in-time hypersensitivity reaction that characterizes DTH. We have presented data demonstrating that the early component of these DTH reactions is a $T$ cell and mast cell dependent component of DTH during which mast cell release of serotonin causes a local increase in vascular permeability (Kops et al., 1983; Van Loveren et al., 1983, 1984). This allows circulating $T$ cells to enter the extravascular tissue. Some of these $T$ cells are antigen specific, and following interaction with local antigen they release various lymphokines that attract circulating bone marrow-derived leukocytes which infiltrate the tissue producing the classical late component of DTH reactions.

This assay used for detecting DTH reactions measures the thickness of the ears of the mice before, and at different times after challenge. Ear thickness can be measured with various instruments; most commonly with an engineers micrometer or with a caliper. This assay, first described by Asherson and Ptak (1968), has proven to be very reproducible, and is employed widely. However, during our studies of the biphasic nature of DTH reactions in challenged ears of contact sensitized mice, we noted that the pattern of ear swelling responses was influenced by the type of instrument used for measurement. Micrometers utilizing a screw with friction thimble detected a biphasic ear swelling pattern that was mentioned above: an early peak at $2 \mathrm{~h}$, a decline at $4 \mathrm{~h}$, and then a delayed and prolonged swelling component at $12-48 \mathrm{~h}$. Using a spring-loaded caliper, that applies light pressure to the ears, we found that the onset of ear swelling reactions was also at $2 \mathrm{~h}$ after challenge, but the decline of ear thickness at $4 \mathrm{~h}$, as noted with the micrometers, was not significant or was even absent. Thus the early component blends into the later component when such a caliper is employed. At the other end of the spectrum are results obtained with a sliding caliper, that only measures a very small area of the ear, compared to the caliper and micrometers mentioned above. This sliding caliper does not detect a significant swelling reaction early after antigen challenge of the ears, but does detect the late reactions that begin at $12 \mathrm{~h}$. The reason for these differences probably lies in the different pressure that is applied to the ears by the various instruments. These data are discussed in terms of the mechanisms that account for ear swelling reactions during the various stages in the development of DTH reactions.

\section{Materials and Methods}

Mice

Male CBA/J mice, 5-7 weeks old, were obtained from the Jackson Laboratory, 

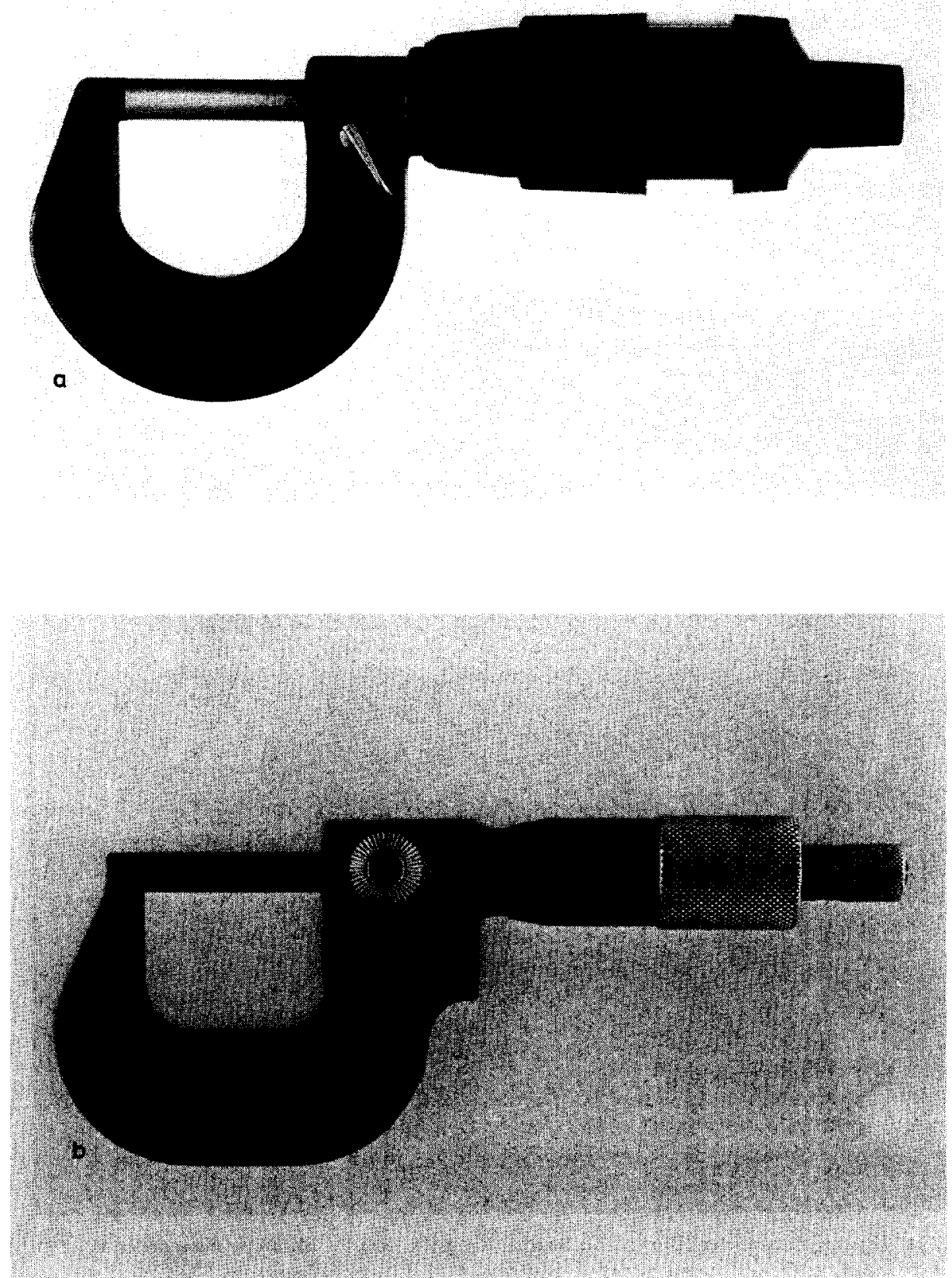

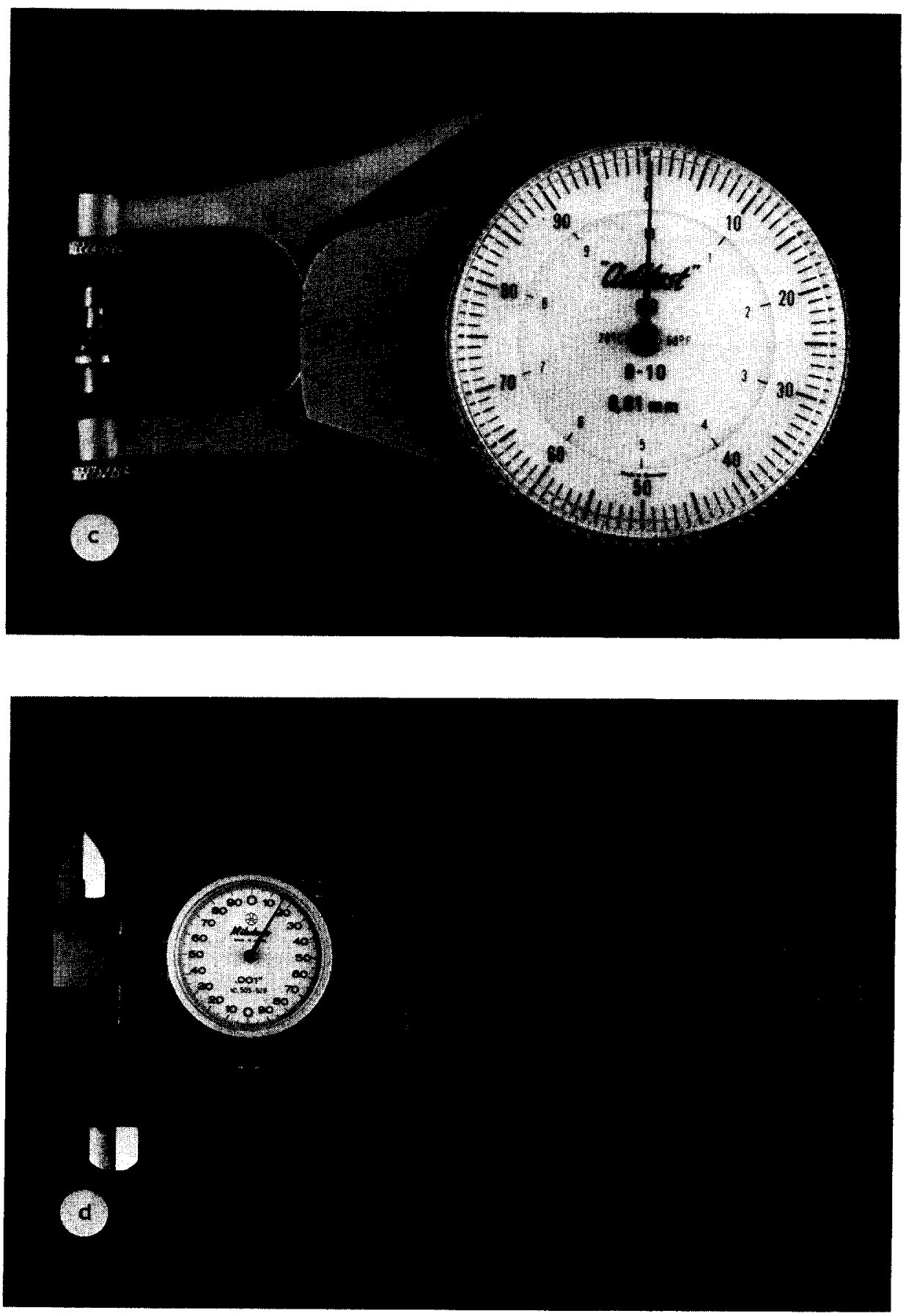

Fig. 1a: Digimic micrometer (Brown and Sharpe, Kingston, RI). b: Mitutoyo micrometer no. 193-10 (Tokyo, Japan). c: Oditest spring caliper. d: Mitutoyo 4" dial (sliding) caliper no. 505-629. 
Bar Harbor, ME, and were rested at least 1 week in an air filtered enclosure before use.

Picryl chloride (PCL)

Picryl chloride (Chemotronix, Swannanoa, NC) was recrystalized 3 times from methanol $/ \mathrm{H}_{2} \mathrm{O}$ before use, and was stored protected from light in a dessicator at room temperature.

\section{Contact sensitization of mice}

CBA mice were contact sensitized by topical application of $0.15 \mathrm{ml}$ of $5 \%$ PCL in absolute ethanol and acetone $(3: 1)$ to the shaved abdomen, chest, and 4 feet.

\section{Measurement of ear swelling responses}

Four days after active sensitization, both ears of the mice were challenged by topical application of 1 drop (27-gauge needle) of $0.8 \%$ PCL in olive oil. Prior to, and at various times after challenge, duplicate measurements of ear thickness were made with various instruments. The increase in ear thickness was expressed as the mean $\pm \mathrm{SE}$ in units of $10^{-3} \mathrm{~cm}$.

\section{Instruments employed to measure ear thickness}

Four types of instruments were used (Fig. 1): Digimic micrometer, Browne and Sharpe, Kingston, RI (Fig. 1a); Mitutoyo micrometer no. 193-10, Tokyo, Japan (Fig. 1b); and Starrett micrometer series 216, Athol MA (not shown, similar to Fig. 1b), all micrometers with friction thimble and lock nut; Oditest, (H.C. Kröplin, Auf der Röthe 5, D-6490, Schlüchtern-1, F.R.G.) (Fig. 1c), a caliper that uses the pressure of a spring, and Mitutoyo 4" dial caliper no. 505-629, Tokyo, Japan (Fig. 1d), a sliding caliper without preset pressure. The Mitutoyo no. 505-629 sliding dial caliper measures the thickness of the ear between 2 surfaces of only $4 \mathrm{~mm}^{2}$; the other instruments measure the thickness of the ear between 2 circular surfaces of $31 \mathrm{~mm}^{2}$.

\section{Results and Discussion}

As described previously (Van Loveren et al., 1983), the time course of DTH ear swelling reactions after challenge of PCL sensitized mice, as measured with a Brown and Sharpe micrometer (Fig. 1a), showed an early component that peaked $2 \mathrm{~h}$ after challenge with PCL, a complete decline at $4 \mathrm{~h}$, and a late reaction, that began $12 \mathrm{~h}$ after challenge, and peaked at $24 \mathrm{~h}$ (Fig. 2a). Measuring ears with the micrometer at different times did not seem to influence future measurements of the same ears, since measurements of a separate group for each time point after challenge produced essentially the same time course as measuring a single group of mice at each time point (Fig. 2a). Using a micrometer of the same type, but from 2 additional manufacturers (Mitutoyo, Fig. 2b; and Starret, data not shown), the time courses of ear swelling responses in actively sensitized mice were essentially the same and did not differ whether ears of 1 group were meàsured at different time points, or whether 

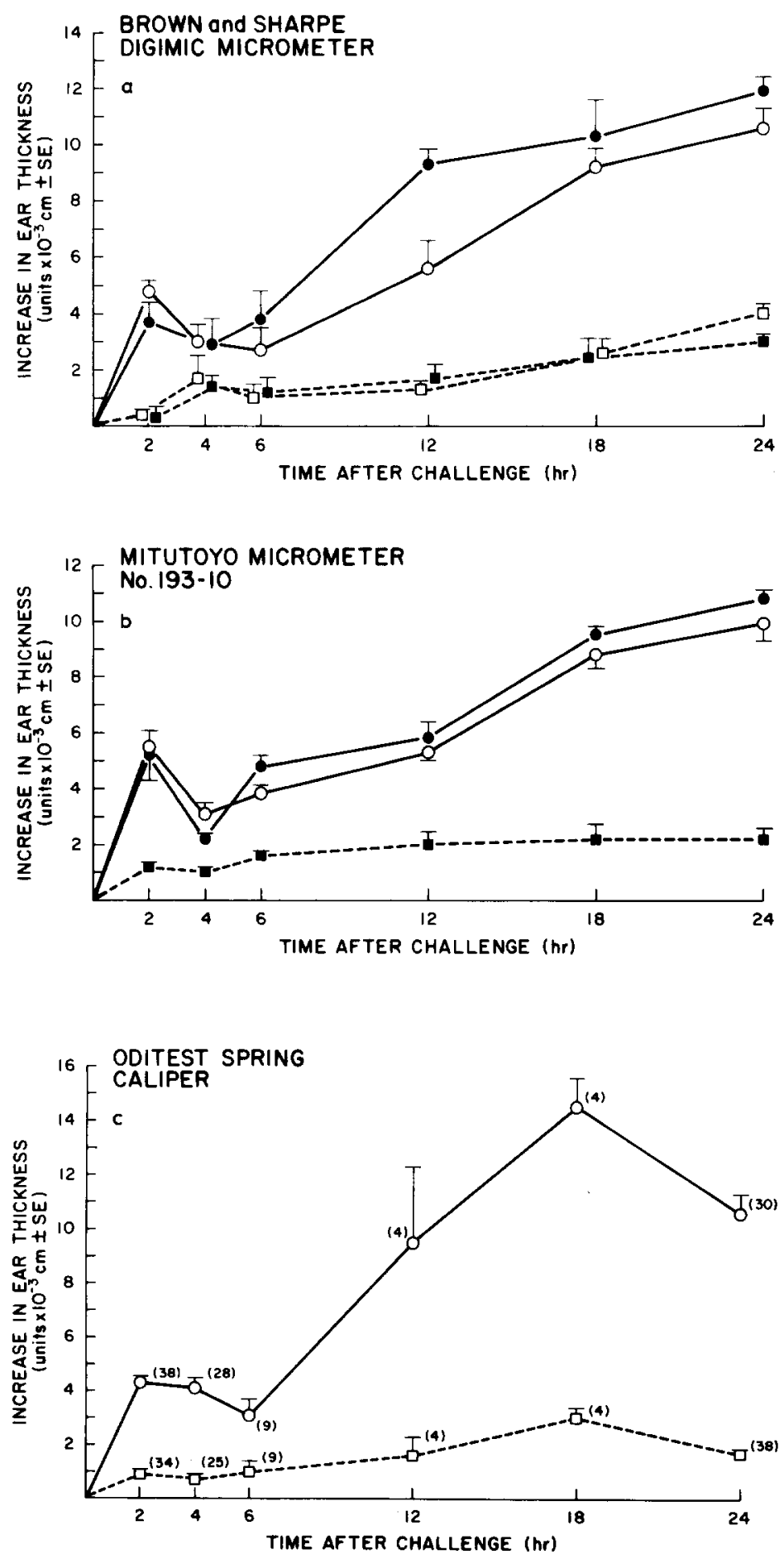


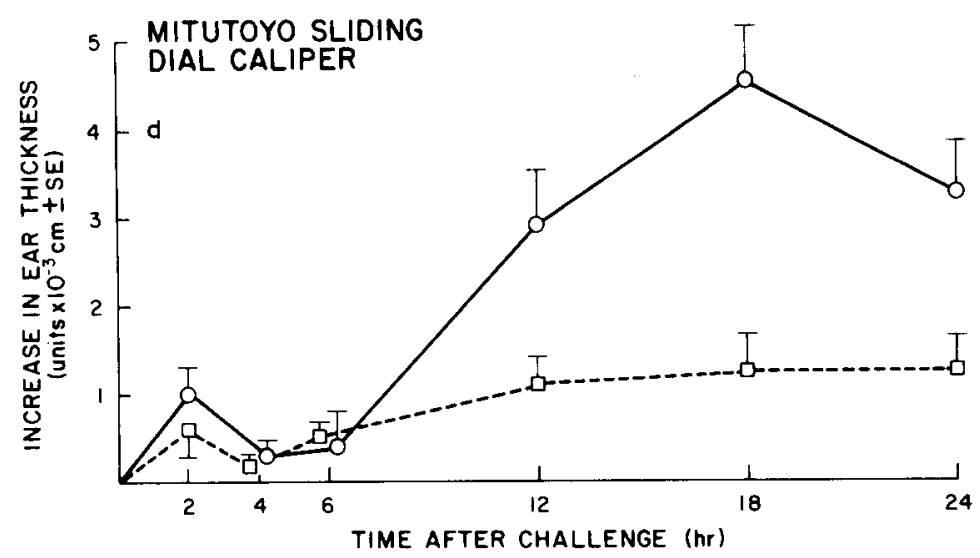

Fig. 2a: time course of ear swelling reactions measured with the Digimic micrometer. CBA mice were actively sensitized by topical application of $0.15 \mathrm{ml} 5 \%$ picryl chloride (PCL) in absolute ethanol and acetone $(3: 1)$ to the shaved abdomen, chest and 4 paws. Four days later both sides of both ears were challenged by topical application of a drop (27-gauge needle) of $0.8 \%$ PCL in olive oil. Groups of mice were used that were measured before and at various time points after ear challenge $(0-0)$, or different groups of mice were used, that were measured before and only once at various time points after ear challenge (-). Also 1 group of control mice were challenged and measured at various times ( $\square-\square$ ), or different groups of control mice were challenged and measured before and at only 1 time point after challenge ( $\square$ ) with the Digimic micrometer. All groups consisted of 4 mice $(N=4)$. b: mice were PCL-sensitized and challenged and the ears were measured as indicated in a, but with the Mitutoyo micrometer, no. 193-10. One group of 7 immunized mice was measured at each time point $(\mathrm{O}-\mathrm{O})$. Different groups of 3 sensitized mice were measured at only 1 time point $(-\bullet)$. One group of 4 control mice was measured at each time point (ロ- $\square$ ). c: mice were immunized with PCL and the ears were measured after local challenge as indicated in a; but the Oditest spring caliper was used. One group of immune mice ( $\square-\square$ ), and 1 group of non-immune controls (口- $\square$ ) were employed. Pooled data of 9 experiments are presented. The number of mice per group is given in parenthesis. d: mice were immunized and ear-challenged with PCL and their ears were measured as indicated in a, but the Mitutoyo no. 505-629 slide caliper was used. One group of immune mice $(\mathrm{O}-\mathrm{O})$ and 1 group of non-immune controls $(\square-\square)$ were employed. Pooled data of 2 experiments are presented $(\mathrm{N}=10)$.

different groups of mice were used at different time points. In contrast to results with the micrometers, when the Oditest spring caliper that is shown in Fig. 1c was used, the ears also showed an increased thickness at $2 \mathrm{~h}$, but a significant increase in thickness was then observed throughout the period of measurement (Fig. 2c). The different patterns of ear swelling measured by the micrometers or caliper were noted in the hands of different individuals who used these instruments. The most dramatically different time course was observed when the Mitutoyo no. 505-629, sliding caliper was used (Fig. 2d): with this instrument alone, no early reaction that was significantly different from swelling in control ears was detected, but starting at $12 \mathrm{~h}$ after ear challenge, the late reactions were observed.

Although we do not have actual data on how much pressure the various instruments apply to the ears, the Oditest spring caliper shown in Fig. 1c, that applies a set pressure via a spring, definitely applies less pressure compared to the 
micrometers applying a pressure set by the friction thimble, whereas the sliding caliper shown in Fig. 1d applies pressure to only a very restricted area of the ear, actually leaving a mark on the ear after reading. We conclude therefore, that the differences in time course patterns are due to differences in pressure applied to the ears by the different instruments. The slide caliper applies a lot of pressure and therefore fails to detect the early component, and measures only a small late component in comparison to the other instruments. In the case of the Oditest spring caliper, where there is only very little pressure, the early component of DTH is measured $2 \mathrm{~h}$ after challenge. This early component is mainly due to increased vascular permeability, in which the extra-vascular tissues do not show a significant influx of blood borne leukocytes (Kops et al., 1983, 1984). Gradually, leukocytes do enter, and account for the prominent $24 \mathrm{~h}$ infiltrate of cells that characterizes DTH reactions (Gray and Jennings, 1955; Asherson and Ptak, 1968). In the case of measuring ear reactions with the micrometers, the early component of DTH is also seen at $2 \mathrm{~h}$ after antigen challenge. However, the subsequent decline in measured ear thickness was either significant but not complete (Fig. 2b), or complete (Fig. 2a), depending on the micrometer used.

This indicates that the actual thickness of the ears at 2 and $4 \mathrm{~h}$ after challenge probably is not different, but that the effect of applying pressure to the ears differs at $2 \mathrm{~h}$ after challenge compared to $4 \mathrm{~h}$ after challenge, accounting for the different patterns. At $2 \mathrm{~h}$ after challenge, the ears cannot be easily compressed, and an increase in ear thickness is measured with all except one of the instruments. This indicates that at $2 \mathrm{~h}$ there is probably an active mechanism of accumulation of, most likely, plasma components in the extravascular tissues. However, at $4 \mathrm{~h}$ the ears can be compressed more easily (Fig. 2a). Moreover, the thickness of the ears probably does not recover either, since $6 \mathrm{~h}$ after challenge ear thickness as measured with this micrometer is also relatively small. This also indicates that the active process of accumulation of plasma components in the extravascular space of the reaction site is optimal at $2 \mathrm{~h}$ and is over by $4 \mathrm{~h}$ after challenge, as is also indicated by permeability studies employing radiolabelled albumin (Kops et al., 1983, 1984).

These data further separate the early component of DTH ear swelling reactions of actively sensitized mice from the late delayed-reactions. The pattern of the later components of DTH reactions does not differ when the micrometers or the calipers are employed (Fig. 2a, b, c, d). These late reactions cannot be compressed easily by applying more pressure with the various instruments, except in the case of the sliding dial caliper (Fig. 2d). The swelling of the late component is caused largely by infiltration of leukocytes and by leukocyte-dependent fibrin deposits (Colvin and Dvorak, 1975) that cannot be entirely squeezed out of the reaction tissue, in contrast to plasma components that account for ear swelling in the early reaction.

We conclude from these data that the choice of the type of instrument used to measure DTH influences the results of kinetic studies. The spring caliper (Fig. 1c) that applies the least pressure to the ears probably gives the most accurate measurement of the actual thickness of the ears at different times after challenge. But some micrometers that apply more pressure (Fig. 1a and b) are more likely to compress the fluid that accumulates in the early, edematous phase of swelling. Thus, these 
micrometers tend to reveal more clearly, as a result of the pressure they apply, the biphasic pattern of the ear responses and the different nature of the early and late components of DTH that cannot be appreciated as readily with the light-pressure spring caliper.

\section{References}

Asherson, G.L. and W. Ptak, 1968, Immunology 15, 405.

Colvin, R.B. and H. Dvorak, 1975, J. Immunol. 114, 377.

Gray, D.F. and J.S. Jennings, 1955, Am. Rev. Tuberc. Pulm, Dis. 72, 171.

Kops, S.K., H. Van Loveren, R.W. Rosenstein, W. Ptak and P.W. Askenase, 1983, Fed. Proc. 42, 1308.

Kops, S.K., H. Van Loveren, R.W. Rosenstein, W. Ptak and P.W. Askenase, 1984, Lab. Invest. in press. Van Loveren, H., R. Meade and P.W. Askenase, 1983, J. Exp. Med. 157, 1604.

Van Loveren, H., S.K. Kops and P.W. Askenase, 1984, Eur. J. Immunol. in press. 